\title{
Cooperación, competencia y dependencia en los paisajes agrarios de Andalucía y Marruecos
}

\author{
Juan A. MÁRQUEZ DOMÍNGUEZ*
}

\section{RESUMEN}

Marruecos aparece como un país cercano en distancia y estructura geológica, pero lejano en su sistema social, productivo y estructuras políticas. De esta forma, el amplio frente marítimo de Andalucía se convierte, por antonomasia, en la frontera de Marruecos con Europa. A pesar de ello, Marruecos sigue siendo el gran desconocido de los españoles y andaluces, a lo que contribuye la imagen de inseguridad de los últimos años, propiciada por el avance del fundamentalismo musulmán. En este contexto, se hacen necesarios nuevos escenarios de cooperación que permitan amortiguar las contradicciones entre la competencia de las agriculturas marroquíesandaluzas-españolas y la dependencia andaluza-española de mano de obra marroquí.

\section{ABSTRACT}

Morocco may be close in terms of distance and geological structure, but it is distant as regards its social and production systems, and political structures. The extensive Andalusian sea coast is thus, par excellence, the Moroccan border with Europe. Nonetheless, Morocco is still the great unknown for Spanish and Andalusian people, which is reinforced by the image of instability of recent years, fuelled by the advance of Islamic fundamentalism. It is therefore necessary to create new cooperation forums to bridge the gap between the Moroccan-Andalusian-Spanish agricultural competition and the Andalusian-Spanish dependency on Moroccan labour.

* Instituto de Desarrollo Local. Universidad de Huelva. 
Salvado el paso de Despeñaperros, se entra en Andalucía que se muestra como un territorio diverso, conformado esencialmente por la orogenia Alpina y los procesos de modelado cuaternarios y, más al sur, pasadas las aguas del Océano Atlántico y las del Mar Mediterráneo, Marruecos aparece como un país cercano en distancia y estructura geológica, pero lejano en su sistema social, productivo y estructuras políticas. De esta forma, el amplio frente marítimo de Andalucía se convierte, por antonomasia, en la frontera de Marruecos con Europa.

No es una frontera cualquiera, porque posee un fuerte valor estratégico para las políticas migratorias y sistemas productivos europeos, españoles y andaluces. Especialmente el sector agrario presenta un doble componente, a veces contradictorio, para la logística de los campos andaluces:

1. Ser un competidor de determinadas producciones de vanguardia, principalmente con los campos onubenses y almerienses.

2. Ser un mercado laboral de vital importancia para la existencia de los sistemas agrarios andaluces y españoles.

A pesar de ello, Marruecos sigue siendo el gran desconocido de los españoles y andaluces, a lo que contribuye la imagen de inseguridad de los últimos años, propiciada por el avance del fundamentalismo musulmán. En este contexto, se hace necesario nuevos escenarios de cooperación, que permitan amortiguar las contradicciones entre la competencia de las agriculturas marroquíes-andaluzasespañolas y la dependencia andaluza-española de mano de obra marroquí.

\section{COOPERACIÓN OFICIAL DE INVESTIGACIÓN ANDALUCÍA- MARRUECOS.}

A pesar de la cercanía de Marruecos y la existencia de paisajes similares con Andalucía, existe un persistente desconocimiento a nivel general de Marruecos, lo cual contrasta con la necesidad de analizar sus agriculturas porque, entre otras cuestiones, son espacios de competencia, de nuevos yacimientos de empleo y viveros de mano de obra, amén de cuestiones de índole cultural y social. Quizás por ello, la Junta de Andalucía ha tenido una especial preocupación por las relaciones 
Andalucía-Marruecos, y ha tratado de enmarcarlas dentro del contexto fronterizo de la Unión Europea.

A partir de ello, "El Proyecto de Cooperación en Investigación Agraria Andalucía - Marruecos -PCIAAM- se enmarca dentro de la iniciativa comunitaria Interreg III A España-Marruecos y está liderado por el Instituto de Investigación y Formación Agraria y Pesquera -IFAPA-. Cuenta con la participación de la Dirección de Formación, Investigación y Desarrollo -DERD- del Ministerio de Agricultura, Desarrollo Rural, y Pescas Marítimas del Reino de Marruecos.

EI PCIAAM tiene como finalidad contribuir al establecimiento de relaciones sólidas de colaboración e intercambio en materia de investigación agraria entre las instituciones de investigación andaluzas y marroquíes, en relación al Norte de Marruecos.

Las zonas de intervención del PCIAAM son las provincias de Málaga, Cádiz, Sevilla, Granada, Huelva y Córdoba y el norte de Marruecos, con doce provincias agrupadas en las regiones de Tánger - Tetuan, Taza - Alhucemas - Taunat y Oriental."(Junta de Andalucía, 2008).

La cooperación oficial para el desarrollo transfronterizo de Andalucía con Marruecos, entre 2003-2007, ha estado centrada en aspectos del desarrollo económico: agricultura y desarrollo rural, fomento de la economía social y del empleo, comercio interior, cooperación empresarial y turismo.

El eje Agricultura y Desarrollo Rural, que ahora interesa, se ha centrado esencialmente en 5 actuaciones, cuyo perfil muestra sectores de retaguardia 0 , al menos, tradicionales:

1. Desarrollo rural.

2. Olivicultura.

3. Ganadería caprina.

4. Gestión del agua de riego.

5. Modernización del sector agroindustrial. 
Las actuaciones se han beneficiado de fondos Interreg IIIA y han implicado a universidades y centros de investigación andaluces. Caben resaltar las siguientes, en los sectores de aromáticas, olivar, almendro, caprino y uso del agua.

A continuación se establece, brevemente, el perfil de cada una de las actuaciones más importantes, en las cuales se han visto implicadas especialmente, desde la vertiente andaluza el Instituto de Investigación y Formación Agraria y Pesquera de la Junta de Andalucía y la Universidad de Córdoba.

A- Proyecto para el análisis del comportamiento de las plantas aromáticas y medicinales en ambientes áridos, desarrollado entre enero 2004 y abril 2007. Contó con el apoyo de fondos Interreg III A España- Marruecos y tuvo como coordinador a Pedro Cermeño. Este proyecto ha propiciado encuentros en Rabat y Meknes.

B- Caracterización del olivo cultivado y silvestre en las zonas oleícolas del Norte de Marruecos y de Andalucía para una mejor utilización de los recursos genéticos locales y enriquecimiento de la composición varietal». Es un proyecto de cooperación en materia de investigación agrícola Andalucía-Marruecos. Interreg España, que fue coordinado por Juan M. Caballero del Instituto Insvestigación y Formación Agraria y Pesquera, IFAPA Córdoba. Este proyecto ha propiciado encuentros en Meknes y tiene especial relevancia para el sector del olivo marroquí que ocupa más de 300.000 hectáreas y representa una parte muy importante del patrimonio arbóreo marroquí, aunque todavía brilla por la ausencia de buenas practicas agrícolas.

C- Jornadas técnicas y mesas redondas de trabajo sobre el almendro en Alhucemas y Targuisti, con objeto de dar a conocer los estudios y experiencias sobre el almendro y fomentar el debate sobre la problemática actual y acciones a emprender. Fueron coordinadas por Octavio Arquero Quilez, del Instituto Insvestigación y Formación Agraria y Pesquera, IFAPA Córdoba.

D- Jornadas de Estudio sobre el Caprino en Tánger, cordinadas por Francisco Arrebola. Fueron el resultado de un protocolo de colaboración entre el consejero de Agricultura y Pesca, Isaías Pérez Saldaña, y el secretario de Estado de Agricultura, Desarrollo Rural y Pesca Marítima del Reino de Marruecos, Mohamed Mohattane. 
El objetivo es cooperar técnicamente en materia de ganadería caprina y sanidad animal, en especial en el Norte de Marruecos. Ésto permitirá la creación de un observatorio conjunto de las enfermedades emergentes, dada la cercanía entre el Reino de Marruecos y la comunidad andaluza, la presencia de sectores ganaderos similares y el importante tránsito entre ambos territorios, lo que ha dado lugar a que se inicien los trabajos que permitan aplicar medidas de vigilancia y lucha contra las enfermedades, especialmente las de carácter vectorial como la lengua azul. Marruecos cuenta en la actualidad con más de tres millones de reses caprinas y más de 900.000 se encuentran en el Norte del país (aula-arabe.com, 2007).

E- "Metodologías de análisis económico del uso de agua en la agricultura: problemas institucionales y de gestión", los investigadores responsables fueron por Andalucía Javier Calatrava Requena y por Marruecos: Mohammed El Amrani. Parte de la actividad se desarrollo en Meknes y tenía como objetivo el mejor aprovechamiento del agua como recurso valioso y escaso.

En conclusión, la cooperación oficial de investigación Andalucía-Marruecos en el sector agrario ha estado centrada en actuaciones interesantes desde el punto de vista científico y del establecimiento de relaciones de colaboración e intercambio en materia agraria, pero ha pasado superficialmente por los temas complejos de mercados laborales, comercio agrícola y frentes de agricultura de vanguardia, donde se establecen fuertes relaciones de dependencia y competencia.

\section{FRENTES AGRÍCOLAS DE COMPETENCIA Y DEPENDENCIA.}

Aunque desde fuera, Marruecos suele aparecer como un país árido, cuenta con un paisaje de una variedad espectacular. Entre los sistemas orográficos del Rif y Atlas aparecen llanuras, altiplanos y valles fértiles y bien irrigadas. Existen grandes diferencias entre áreas húmedas, en torno al Rif Occidental y Central, que reciben más de $600 \mathrm{~mm}$ al año, la zona semi-árida, que cubre la mayor parte del dominio de la cordillera del Atlas, con menos de 600, la árida, con menos de $200 \mathrm{~mm}$ y zona sahariana al sur del país, donde no es posible la agricultura, a no ser que se cuente con riegos durante todo el año. 


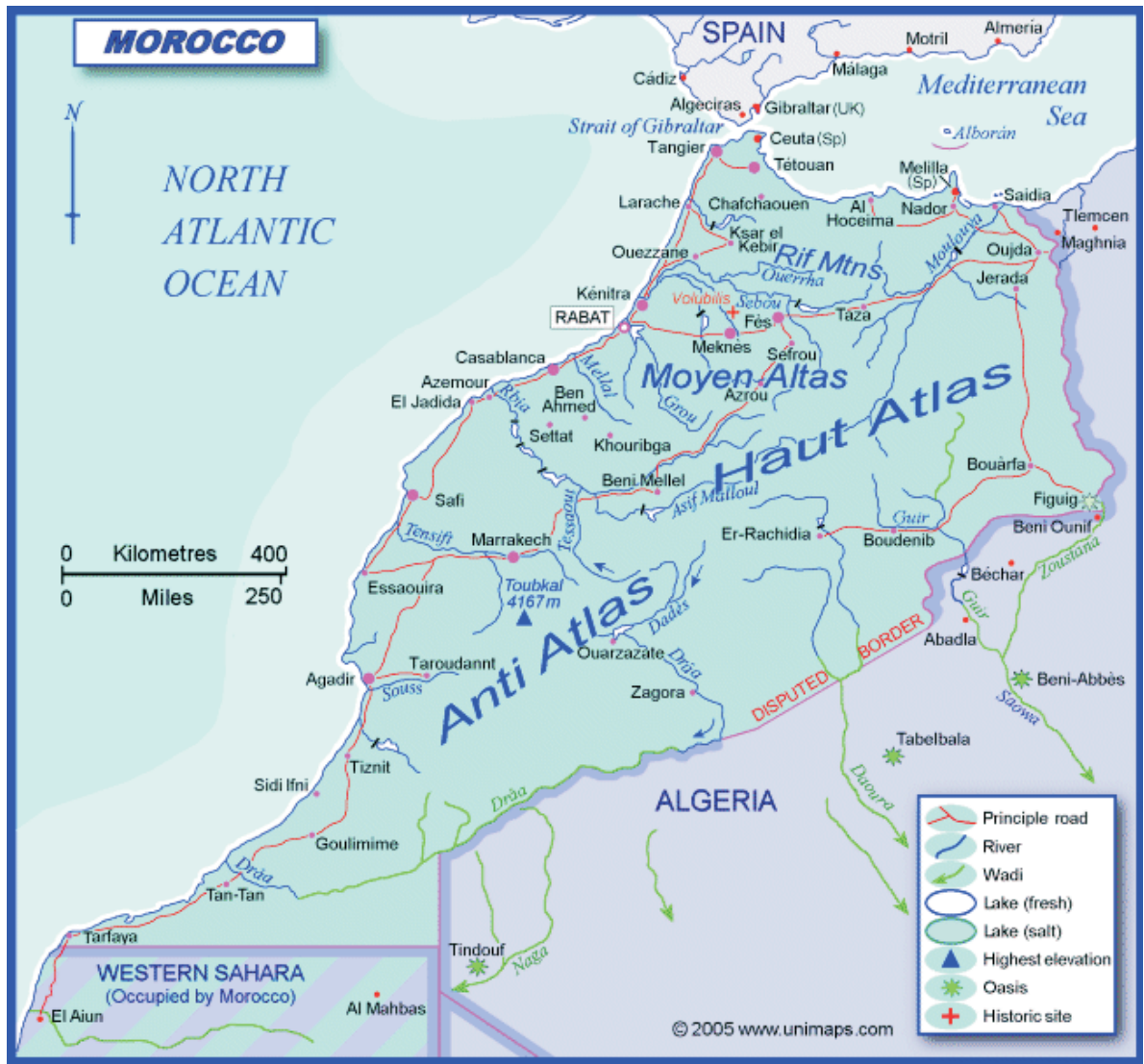

Mapa hidrológico 2005. Fuente www.unimaps.com

En general, la costa Atlántica marroquí, especialmente la norte, se aprovecha de la escorrentía de los ríos y, por sus características climatológicas y posibilidades edáficas e hidrológicas, presenta frentes agrícolas similares a los de Andalucía, cuyas producciones, en gran parte, concurren en los mismos mercados y, por tanto, pueden convertirse en focos de conflictos y de competencia. La existencia de paisajes que caminan paralelos a ambos lados de la frontera agraria andaluza-marroquí, están poco estudiados y son escasamente conocidos a nivel institucional y, en ellos impera la iniciativa privada, cuya ágil dinámica, como ha ocurrido en las fronteras agrarias de las provincias de Huelva y Almería, aparece opaca al lento observar de las administraciones. 


\section{Tabla 1. Área cosechada, en miles de hectáreas}

\begin{tabular}{|l|r|r|r|}
\hline Paisajes consolidados, año 2005 & España & Marruecos & Andalucía \\
\hline Área cosechada (1000 ha) & $(1)$ & 1 (1) & (2) \\
\hline Aguacates & 8.80 & 1.61 & 8.53 \\
\hline Albaricoques & 19.86 & 12.00 & 0,24 \\
\hline Cerezas (incl. Guindas) & 25.86 & 1.30 & 3,01 \\
\hline Ciruelas y endrinas & 19.57 & 7.90 & 2,65 \\
\hline Limones y limas & 47.31 & 1.00 & 8,16 \\
\hline Melocot. (duraznos) y nect & 78.45 & 4.50 & 11,35 \\
\hline Naranjas & 135.67 & 48.85 & 44,58 \\
\hline Peras y membrillos & 37.47 & 7.20 & 1,16 \\
\hline Tangerinas, mandarinas y clementinas & 118.36 & 24.00 & 11,60 \\
\hline Fresas & 7.60 & 3.14 & 7,31 \\
\hline Ajo & 18.00 & 4.10 & 6,30 \\
\hline Alcachofas & 18.60 & 3.65 & 2,95 \\
\hline Berenjenas & 3.00 & 2.55 & 2,44 \\
\hline Calabaza, zap., calab. confit. & 7.00 & 6.78 & 4,74 \\
\hline Cebollas (incl. chalotes) & 24.60 & 29.60 & 3,85 \\
\hline Chiles y pimientos, en verde & 23.50 & 6.54 & 16,64 \\
\hline Coles y otras cruciferas & 7.70 & 1.70 & 1,49 \\
\hline Coliflor y brécol & 25.40 & 2.02 & 1,40 \\
\hline Espárragos & 12.00 & 0.39 & 7,30 \\
\hline Jud. verd., incl. habich. v. & 17.50 & 17.63 & 9,16 \\
\hline Lechuga y achicoria & 36.20 & 0.21 & 11,73 \\
\hline Otros melones (incl. cantalupos) & 38.50 & 27.34 & 9,49 \\
\hline Pepinos y pepinillos & 7.20 & 1.10 & 6,11 \\
\hline Sandías & 15.80 & 12.96 & 8,22 \\
\hline Tomates & 71.90 & 22.10 & 20,12 \\
\hline Zanahorias y nabos + & 5.00 & 16.21 & 4,13 \\
\hline & & &
\end{tabular}

(1): FAOSTAT año 2005| ( F FAO Dirección de Estadística 2007 | 16 octubre 2007

(2): Junta de Andalucía 2005. Media 2001-2004. Consejería de Agricultura y pesca.

Fuentes: FAO y Junta de Andalucía. Elaboración Juan A. Márquez 2007 
El notable incremento de la producción y exportación de hortalizas de Marruecos en los últimos lustros le ha llevado a convertirse en «el principal suministrador extracomunitario de hortalizas del mercado europeo y en el más importante abastecedor del mercado francés por delante de España» (Aznar, José A. 2007). Efectivamente, desde los años noventa, el sector hortícola marroquí realiza una parte considerable de su producción en invernaderos, lo que le permite obtener elevados rendimientos y competir en el mercado europeo en el mismo calendario que las producciones españolas.

Especialmente, la competencia desde Marruecos puede llegar desde los paisajes consolidados en el subsector de los cítricos, con naranjas, mandarinas y clementinas, mientras que, desde los paisajes efímeros, más dinámicos y coyunturales, los subsectores de la fresa, tomates, judías verdes y otras hortalizas están siendo una dura competencia para los mismos productos andaluces, aunque en un mercado globalizado, son muchas las estrategias y logísticas de alianzas empresariales, cuya valoración escapa al alcance de este trabajo. Especialmente el tomate para consumo en fresco, que es la primera hortaliza de exportación de España y Marruecos es fuente de diversos conflictos...

En el contexto marroquí de subdesarrollo, con una renta per cápita de 4.600 dólares, y el $15,9 \%$ de la población por debajo de la línea de la pobreza (Wikipendia 2007), la agricultura concentra el $19,3 \%$ del PIB, frente a la industria con el 35,5 y los servicios con el 45,2 , pero además, la misma agricultura tiene al $40 \%$ de la población activa. Lógicamente, gran parte de esta población, en un contexto de modernización, está subempleada o en situación de paro y constituye un enorme mercado laboral para los nuevos yacimientos de empleo de las fronteras agrarias marroquíes y españolas y, por supuesto, para los frentes agrícolas de Huelva y, en menor medida Almería.

El principal problema marroquí es la imposibilidad de crecer económicamente al ritmo que lo hace su población. El modelo demográfico se caracteriza por una elevada natalidad, con tasas de mortalidad en descenso y una mortalidad infantil elevada, en comparación con la española. 


\section{Tabla 2. Distribución del Producto Interior Bruto y Activos por sectores}

\begin{tabular}{|l|r|r|r|r|r|}
\hline Ambito-Variable & Agricultura & Industria & Servicios & Otros (1) & Total \\
\hline Andalucía PIB & 4,94 & 23,1 & 61,48 & 10,48 & 100 \\
\hline Andalucía Activos & 10,5 & 25,5 & 64,0 & 0 & 100 \\
\hline Marruecos PIB & 19,3 & 35,5 & 45,2 & 0 & 100 \\
\hline Marruecos Activos & 40,0 & 15,0 & 45,0 & 0 & 100 \\
\hline
\end{tabular}

Fuentes: INE, Encuesta de Población Activa (metodología 2005). En porcentaje del total de activos por sectores. Contabilidad Regional Trimestral de Andalucía. Base 2000.

http://fr.wikipedia.org/wiki/\%C3\%89conomie_du_Maroc. (1) Impuestos netos sobre los productos.

\section{Imagen de la zona de Kenitra}

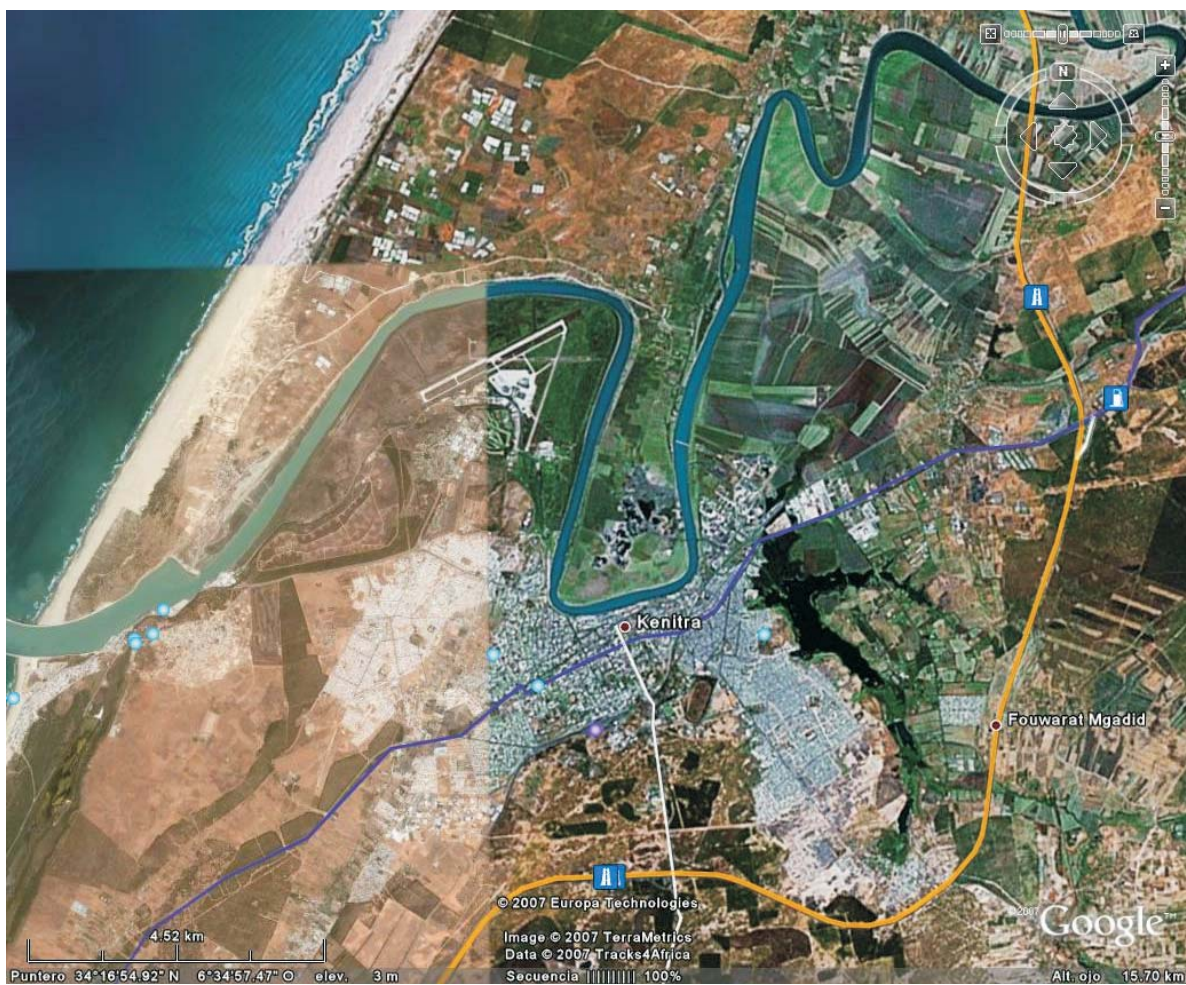

Con estos antecedentes, el sistema productivo marroquí, no es capaz de ocupar a toda la población activa que se incorpora al mercado laboral y propicia, cuando no obliga, a muchos marroquíes a tomar la decisión de emigrar. 
Aunque, el sector agrícola contribuye de manera significativa al PIB total y juega un papel importante en la cobertura de una gran parte de las necesidades alimenticias del país en productos de base como los cereales, los aceites, las leches y carnes, las hortalizas y frutas, todavía mantiene un exceso de población activa agraria, que trabaja sobre una superficie agrícola que se extiende por cerca de 9 millones hectáreas de las cuales más de un millón de hectáreas irrigadas.

En este contexto, sin pretender agotar las posibilidades comparativas de espacios similares y de competencia, en los litorales de las provincias de Huelva y Almería se localizan frentes muy dinámicos, productores de fresas y hortalizas que alcanzan interesantes precios en los mercados españoles y europeos. En un plano similar, la provincias de Larache, en la región Tanger-Tétouan, y Kenitra, en la de La región de Gharb-Chrarda-Béni Hssen, presentan espacios donde se cultivan fresas y hortalizas y tienen un fuerte potencial agrícola, con más del $20 \%$ de la tierra irrigada. Tanto Kenitra como Larache son provincias marítimas, con abundancia de suelos que tienen un perfil edáfico arenoso y poseen importantes recursos hídricos a explotar. También Agadir presenta un amplio frente productor de tomates.

\section{Imagen de Larache}

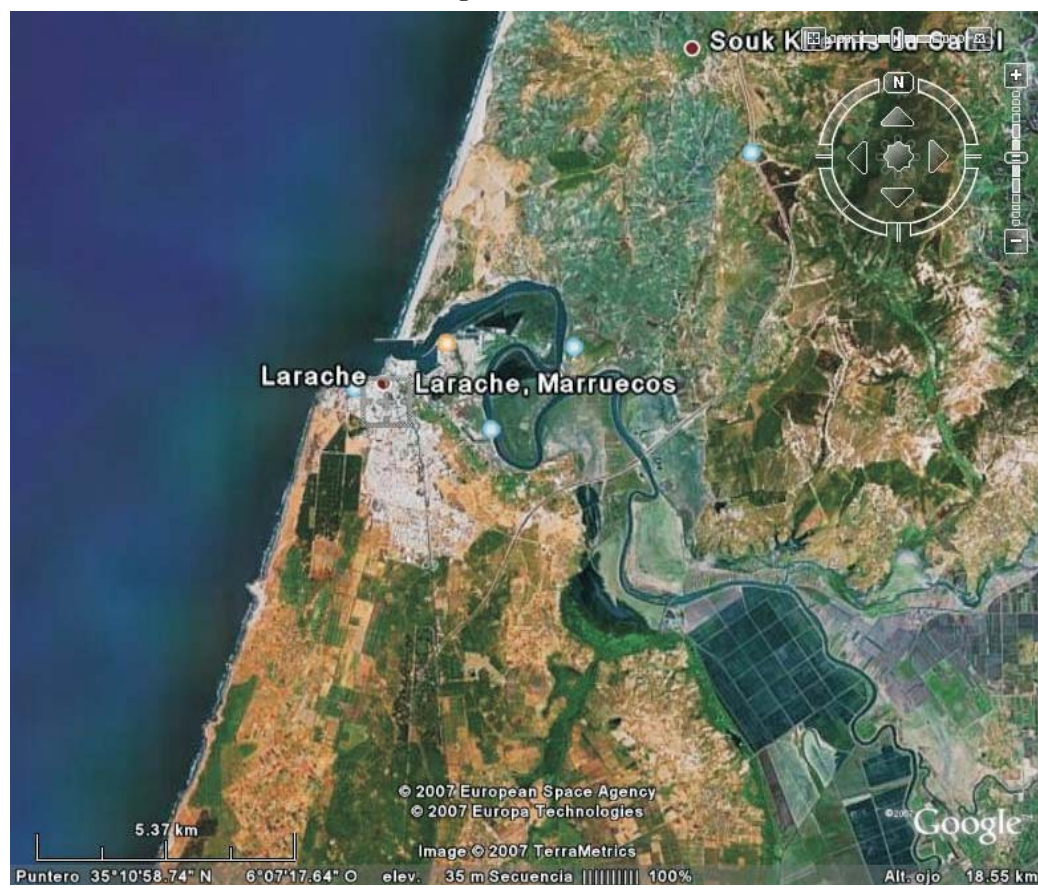

Fuente Google Earth 2007 


\section{DEPENDENCIA ANDALUZA DEL JORNALERO MARROQUÍ.}

El impulso de los sectores productivos de España desde 1993 has. hecho que las actividades económicas necesiten una gran cantidad de mano de obra, no existente dentro de sus fronteras. "En el 2005, el país había creado unos 900.000 empleos netos, de los que cerca de un $40 \%$ fueron ocupados por extranjeros" (Wikipendia, 2007).

Imagen del Campo de Dalias en la provincia de Almería

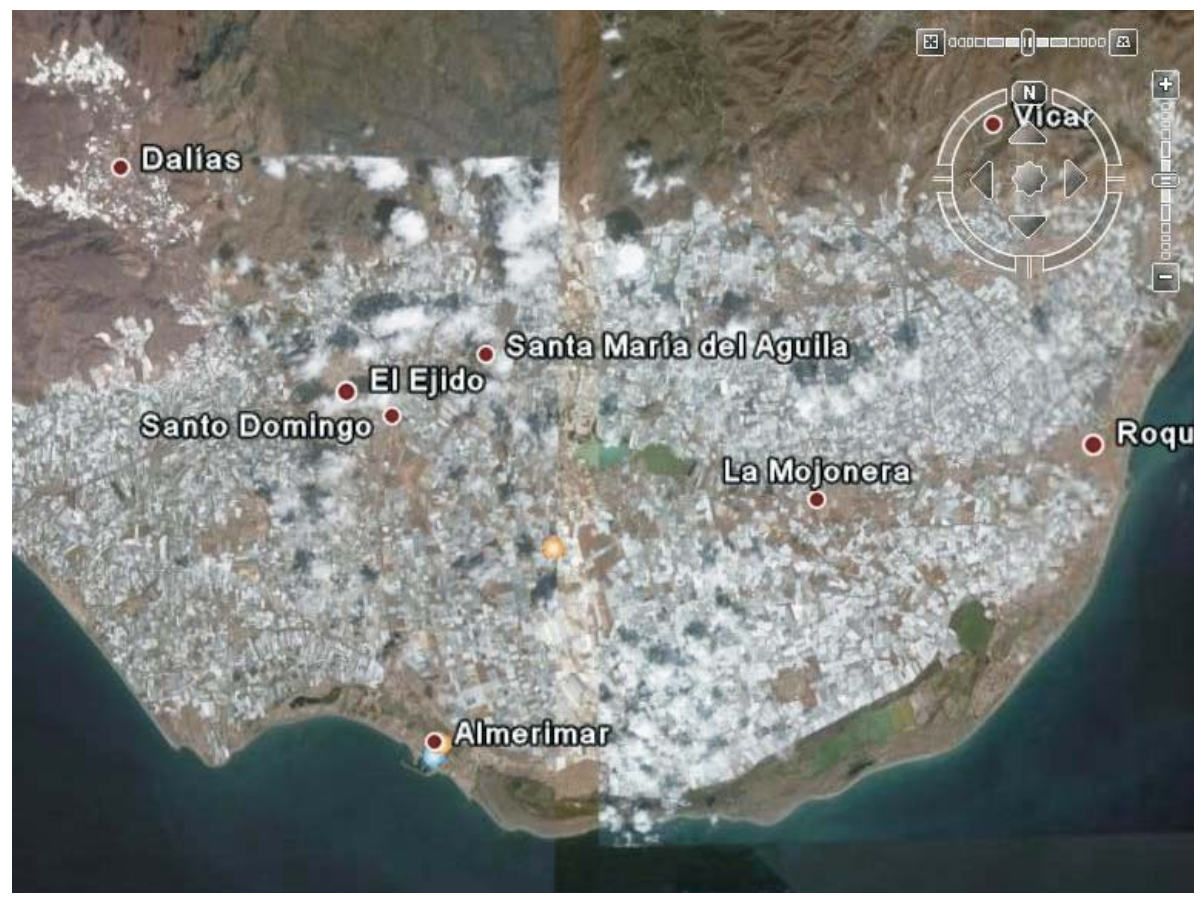

Fuente Google Earth 2007

Especialmente, la llegada del colectivo marroquí ha sido muy cuantiosa, hasta tal punto que se sitúa en el primer puesto por número de inmigrantes de España en el 2007, con 576.344 personas. La mayor parte de ellos ocupan puestos que están catalogados como "profesiones de difícil cobertura", ya sea en los servicios, en la construcción, la industria o la agricultura. Especialmente, los marroquíes trabajan en el sector primario y en Andalucía lo hacen en áreas de agricultura de vanguardia y 
hortícolas. Ello no sólo es un apunte, sino toque de atención a la importancia de aporte de mano de obra marroquí, pues la agricultura de regadío en Andalucía es un sector estratégico para su desarrollo económico y social. "Las más de 893.000 hectáreas de regadío existentes en Andalucía (el $22 \%$ de la superficie cultivada) generan el $57 \%$ de la Producción Final Agraria de la Comunidad Autónoma, y un $60 \%$ del empleo total del sector agrario." (Consejería Agricultura, 2008).

\begin{tabular}{|l|r|r|r|r|r|}
\hline & \multicolumn{7}{|c|}{ Tabla 3. } & & \\
\hline Ambito & Inmigrantes & Marroquís & Has.regadas & \% Invernaderos & Has Invernaderos \\
\hline Andalucia & 531.827 & 86.449 & 893.009 & 5,25 & $47.203,45$ \\
\hline Almería & 116.214 & 34.798 & 74.863 & 36,00 & $26.950,68$ \\
\hline Cádiz & 36.888 & 5.780 & 53.538 & 2,00 & $1.070,76$ \\
\hline Córdoba & 17.087 & 2.125 & 99.273 & 0,50 & 496,365 \\
\hline Granada & 48.874 & 7.487 & 127.846 & 3,00 & $3.835,38$ \\
\hline Huelva & 28.264 & 5.169 & 37.452 & 29,00 & $10.861,08$ \\
\hline Jaén & 14.685 & 4.006 & 202.236 & 0,50 & $1.011,18$ \\
\hline Málaga & 219.955 & 21.251 & 56.002 & 1,00 & 560,02 \\
\hline Sevilla & 49.860 & 5.833 & 241.799 & 1,00 & $2.417,99$ \\
\hline
\end{tabular}

Fuentes: Instituto Nacional de Estadística: Revisión del Padrón municipal 2007. Datos a nivel nacional, comunidad autónoma y provincia Población por nacionalidad, comunidades y provincias, sexo y edad. Consejería de Agricultura, 2008. Elaboración Juan A. Márquez.

Del total de los 576.344 marroquíes residentes contabilizados en España, 86.449 están en Andalucía y, especialmente se concentran en el frente agrícola de vanguardia de Almería, con 34.798 y 21.251 en la provincia de Málaga. De todas formas, el colectivo aún es mayor porque existen inmigrantes invisibles no contabilizados como población residencial. En estos inmigrantes invisibles es posible distinguir entre:

- llegales, cuya cifra es muy arriesgado confirmar sin estudios previos y concienzudos, pero que podría estar en torno al 5-10\% del colectivo marroquí y de ello da cuenta continuamente la prensa a través del apresamiento de algunas de las pateras que atraviesan el estrecho. Las otras pateras, llenan algunas plazas y campos de los pueblos ribereños andaluces. 
- Legales con contratos de origen, que no necesitan, de forma obligatoria, estar empadronados para realizar una estancia de trabajo de uno o varios meses. En el caso de Andalucía, esta forma de inmigración, reviste una gran importancia, especialmente en la campaña de plantación y recolección de la fresa en la provincia de Huelva.

\section{Marroquíes en Andalucía}

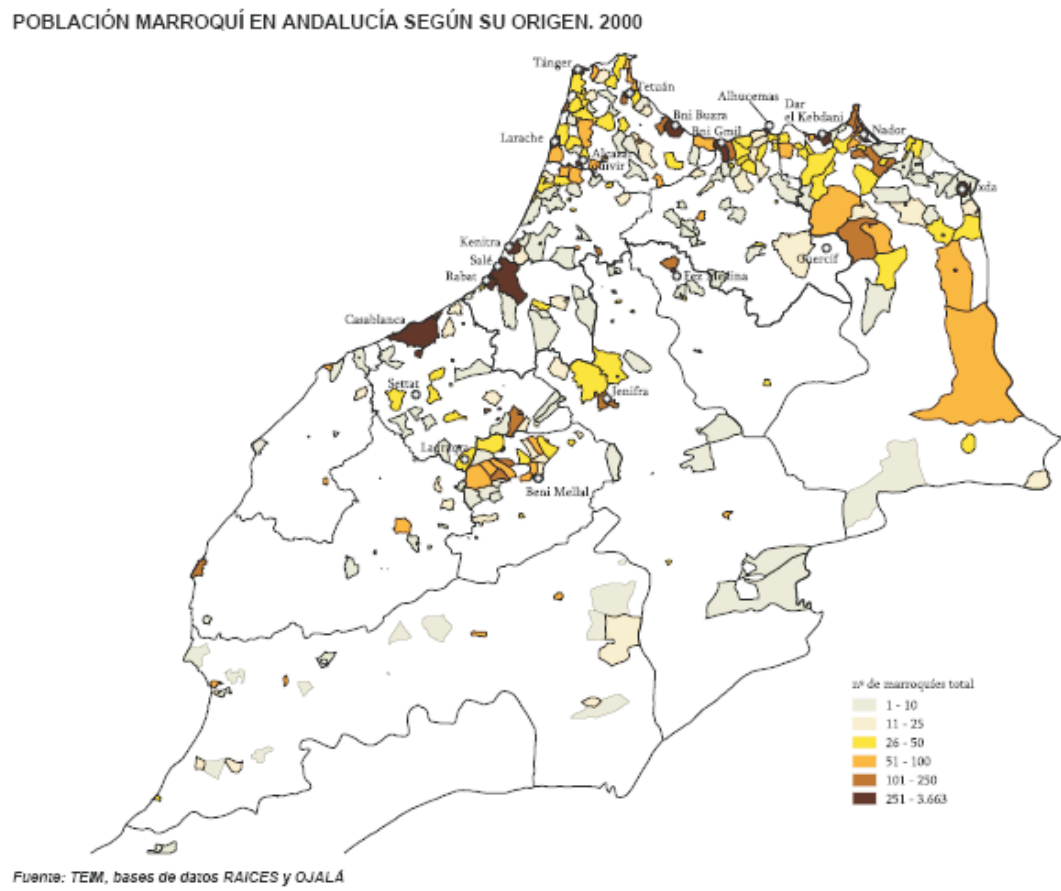

Fuente: Martín, E. y Castaño, E. (2007): marroquíes en Andalucía, en Atlas de la inmigración marroqui en España. http://www.uam.es/otroscentros/ TEIM/Observainmigra /Andalucia/ Andalucia_ index.htm

\section{LA CONTRATACIÓN EN ORIGEN}

"La mejora de las condiciones de vida y el envejecimiento de la población, especialmente en ámbito rural, ha dificultado el aprovisionamiento de mano de obra en la agricultura, hasta tal punto que, en muchos lugares ha hecho peligrar la continuidad de la explotación agraria y, a veces, su desaparición." (Márquez, J.A., 2007; I). Por 
esta causa, la agricultura intensiva, especialmente en el litoral, ha tenido que marcar constantes virajes y estrategias para conseguir la mano necesaria, llevándole a prospectar diversos mercados con fuerza laboral abundante, subempleada o en paro y con diferencias de desarrollo notables que hicieran atractivo los salarios agrarios de Andalucía. En este contexto, Marruecos es un interesante yacimiento de mano de obra para la agricultura andaluza, aprovechada especialmente por la "llamada contratación en origen. Esta modalidad estipula que, una finalizado el tiempo pactado de trabajo, el jornalero retorne a su país, para volver la próxima campaña, si existe demanda.

"La campaña de recogida de la fresa, que comienza en enero de 2008, tendrá en Huelva un acento distinto al de otros años. Por primera vez, las trabajadoras marroquíes contratadas en origen superarán en número a las de Europa del Este y, en concreto, a las procedentes de Rumania que, en los últimos años, se había convertido en el contingente mayoritario" (Freshuelva, 2008). Se espera que en la campaña de 2008 lleguen con contratos de origen un mínimo de 12.000 marroquíes, 11.000 rumanos y unos 4.000 ucranios, además de otros colectivos menos representativos.

Imagen de invernaderos en la provincia de Huelva

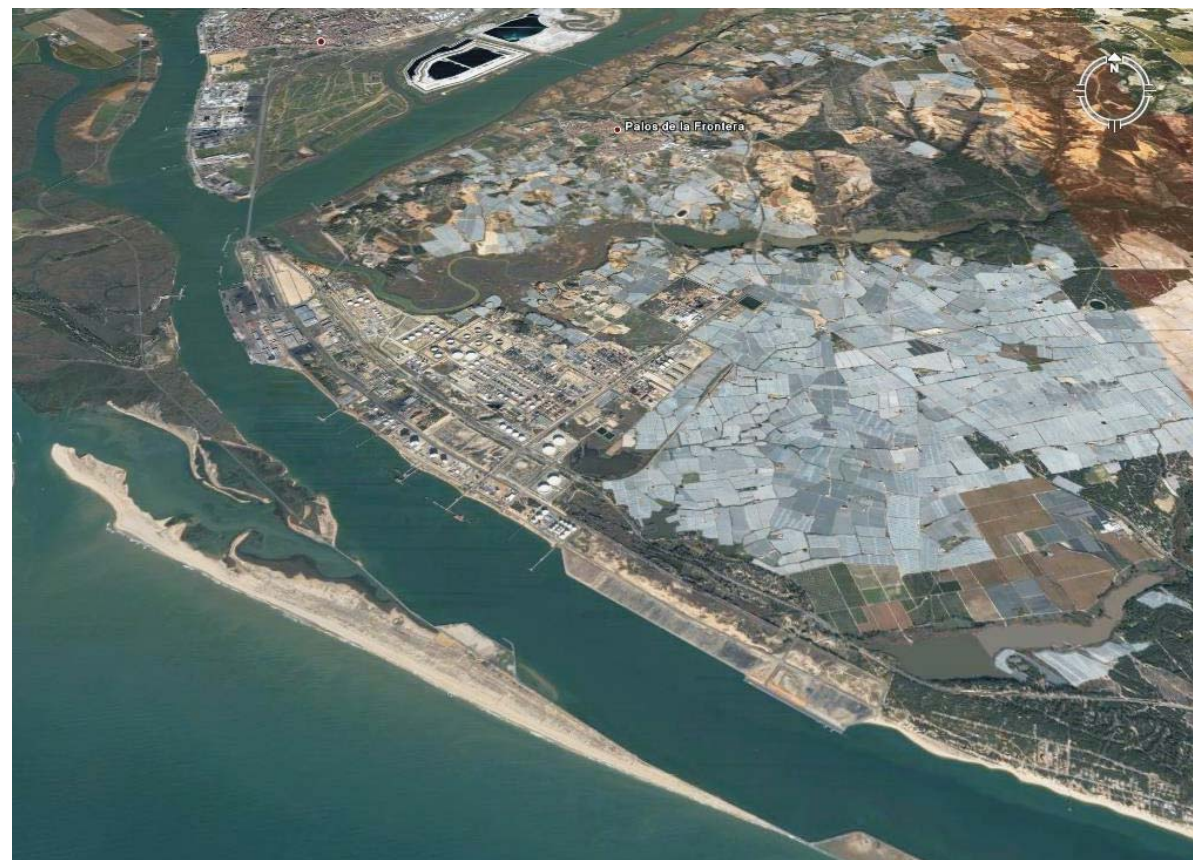

Fuente Google Earth 2007 
El aumento y la confianza en el jornalero marroquí, se debe a un cambio radical en la contratación en origen, que ha reducido enormemente "la fuga de trabajadores", al ponerse en práctica las directrices del proyecto Aeneas, abalado por la Unión Europea y liderado por el Ayuntamiento de Cartaya, que incide en la contratación preferente de mujeres con cargas familiares en Marruecos, lo que garantiza en gran medida la vuelta a Marruecos a final de campaña y el retorno a España en la próxima campaña.

Tabla 4. Trabajadores contratados en origen en la provincia de Huelva por nacionalidad y año

\begin{tabular}{|c|c|c|c|c|c|c|c|}
\hline Nacionalidad & 2002 & 2003 & 2004 & 2005 & 2006 & 2007 (1) & $2008(2)$ \\
\hline Polonia & 4.954 & 7.535 & 8.811 & 7.361 & 9.796 & - & - \\
\hline Marruecos & 336 & 95 & 635 & 1.094 & 2.330 & 7.446 & 12.000 \\
\hline Rumania & 970 & 4.178 & 10.933 & 13.186 & 19.153 & 26.278 & 11.000 \\
\hline Colombia & 149 & 177 & 105 & 82 & 8 & 2 & 2 \\
\hline Ecuador & & 15 & 8 & 64 & 26 & 12 & 12 \\
\hline Bulgaria & & & 508 & 604 & 941 & 2.577 & 2.500 \\
\hline Ucrania & & & & & & 724 & 4.000 \\
\hline $\begin{array}{l}\text { Total contratos } \\
\text { origen }\end{array}$ & 6.409 & 12.000 & 21.000 & 22.391 & 32.254 & 31.539 & 29.514 \\
\hline Has. Fresas & 6.700 & 7.120 & 6.534 & 6.692 & 6.800 & 6.326 & 6.100 \\
\hline Jornales año & 4.757 .000 & 5.055 .200 & 4.639 .140 & 4.751 .320 & 4.828 .000 & 4.491 .460 & 4.331.000 \\
\hline
\end{tabular}

(1): Respecto al colectivo polaco, al disfrutar ya de la plena libertad de circulación laboral, no se incluyen en las estadísticas de contratos en origen de la Subdelegación del Gobierno. Por otra parte, a mediados de campaña 2007, de manera casi improvisada, los agricultores confiaron en un programa europeo, liderado por el Ayuntamiento de Cartaya, destinado a facilitar la gestión de los contratos en origen en Marruecos. Aquello salvó la campaña, pues permitió la llegada de 5.500 marroquíes que se añadieron a los 1.946 pactados. (2) Estimaciones y cifras provisionales de J.A. Márquez. Fuentes: Bago,

M. J., 2007, Ministerio de trabajo y Asuntos Sociales 2006, FresHuelva 2008 y Junta de Andalucía 2008: Avance de superficies y producciones a 31 de enero del año 2.008. Elaboración J.A. Márquez 2008. 


\section{BIBLIOGRAFÍA Y FUENTES DOCUMENTALES UTILIZADAS.}

ADAM, P. y CANSAN, P. (1998): Los contratos temporales en España e Italia. Factoría. Febrero-Mayo 1998.

AULA-ARABE.COM (2007): Informe sobre el sector caprino, en WWW, 2007; aula-arabe.com/?=42.

AZNAR, JOSÉ A. (2004): El sistema de comercialización y exportación de las hortalizas marroquíes. Distribución y Consumo, noviembre-diciembre 2004.

BAGO, M. J. (2007): "Inmigración en la provincia de Huelva", en Comandancia de la Guardia Civil de Huelva Orientaciones para la prestación del Servicio Rural. Diputación Provincial de Huelva y Comandancia de la Guardia Civil, pp. 13-32.

BLEU-MAROC (2007): Carte geographique Maroc, en http://www.bleumaroc.com/carte- geographique.htm.

CHARRO, P. (2003): Derecho Laboral y extranjeros: sistemas de contratación de extranjeros. Análisis de la jurisprudencia, Ponencia presentada al XIII Encuentro de abogados sobre Derecho de Extranjería, Palma de Mallorca, 12-14 junio, www.extranjeria.info.

FAO (2007): Áreas cosechadas en el mundo. Marruecos-España. FAOSTAT año 2005|, Dirección de Estadística 2007, en www/fao.org

FRESHUELVA (2008): Declaraciones al País. El País 19/12/2007.

GARCIA, A. (2006): "Cambios tecnológicos y flujos migratorios. El caso de la agricultura intensiva en Almería", en II Simposium Internacional sobre Desertización y migraciones.

GONZÁLEZ, L. (1996): "Producción integrada en el cultivo de la fresa en Huelva", en Anuario de la Fresa 1996. Edit. CYTA S.L. Huelva. Pp. 50-55. 
GOOGLE EARTH (2007): Imágenes de las provincias de Kenitra, Larache, Almería y Huelva.

GORDO, M. (2002): La inmigración en el paraíso. Integración en la comarca de Doñana, Consejería de Asuntos Sociales de la Junta de Andalucía, Sevilla.

GORDO, M. (2005): "Peones con casilla: el alojamiento de los trabajadores extranjeros con contratos en origen de temporada en la provincia de Huelva", en Actas del XIX Congreso de geógrafos españoles "Espacios públicos, espacios privados. Un debate sobre el territorio", AGE y Universidad de Cantabria, Santander, Versión electrónica, $13 \mathrm{pp}$.

JUNTA DE ANDALUCIA (2007): Sobre la Situación Socioeconómica de Andalucía 2005, en http://www.juntadeandalucia.es/empleo/ces/dictamen/informe_ sobre_situacion_socioeconomica.

JUNTA DE ANDALUCIA (2008): Programa de Desarrollo Transfronterizo http: //www.juntadeandalucia.es/innovacioncienciayempresa/ifapa/pciaam/servlet/ FrontCo ntroller?ec=pciaam.

JUNTADEANDALUCÍA (2007): Cultivos y aprovechamientos 2005. Consejería de Agricultura y pesca. Sevilla, en http://www.juntadeandalucia.es/.

JUNTA DE ANDALUCÍA (2008): Informe sobre el regadío en Andalucía. Consejería Agricultura, http://www.juntadeandalucia.es/.

JURADO, J.M. (1997): "La flor del azahar. Los naranjos en Cartaya". En artes, costumbres y riquezas de la provincia de Huelva, Tomo II. Mediterráneo, Madrid, pp.341-356.

INE (2007; I): Contabilidad Regional Trimestral de Andalucía. Base 2000. año 2005, en www/ine.es.

INE (2007; II):, Encuesta de Población Activa, en www/ine.es. 
INE (2007; III): Revisión del Padrón municipal 2007. Datos a nivel nacional, comunidad autónoma y provincia Población por nacionalidad, comunidades y provincias, sexo y edad, en www/ine.es.

LÓPEZ y MEDINA (1996): "Breve repaso al cultivo de la fresa en Europa", en Revista Agrocosta IX edición, Lepe. Pp. 6-21.

MÁRQUEZ, J. A. (1986): La Nueva Agricultura Onubense. I.D.R. de la Universidad de Sevilla.

MÁRQUEZ, J. A. -coordinación-: (1994) Campesinos sin tierra y territorio jornalero en Andalucía. Indelo, S. Juan 118 pp. ISBN 84-605-0537-5

MARQUEZ, J.A. -dirección- (2001): Posibilidades logísticas de transporte de fresas y cítricos por el puerto de Huelva. Autoridad Portuaria de Huelva, Sevilla.

MÁRQUEZ, J. A. y GORDO, M. (2007): "Temporeros extranjeros en Huelva (España) con contratos en origen: colombianos y ecuatorianos", en Actas del XII Congreso Internacional de la Asociación Española de Americanista, "Huelva y América». Pendiente de publicación.

MARQUEZ, J.A. (2007; I): Territorio y empleo., de la caja negra al casillero múltiple de los lugares. Revista de Empleo n¹4. Consejería de Empleo, Junto de Andalucía, pp. 42-46

MÁRQUEZ, J.A. (2007; II). : Migraciones circulares. Contratos en origen y Co-desarrollo. Congreso de Ciencia Regional. Universidad de Almería, Asociación española de Ciencia Regional Andalucía.

MARTÍN, E. y CASTAÑO, E. (2007): Marroquíes en Andalucía, en Atlas de la inmigración marroquí en España. http://www.uam.es/otroscentros/ TEIM/ Observainmigra /Andalucia/ Andalucia_index.htm 
MINISTERIO DE TRABAJO Y ASUNTOS SOCIALES (2006): EI mercado de trabajo en la Agricultura de Huelva. La inmigración en la agricultura 2000-2004. Observatorio Ocupacional de la Dirección Provincial del Inem-Spee. Documento de Trabajo

MINISTERIO DEL INTERIOR (2007): Balance de la lucha contra la inmigración ilegal 2006, Nota de prensa fechada en Madrid, el 21 de febrero de 2007, www.mir.es.

MORALES, A. (1997): Aspectos geográficos de la horticultura de ciclo manipulado en España. Universidad de Alicante.

MOSANGI, G. .(2007): Codesarrollo, en WWW :codesarrollo- Mosangi cideal.org/images/codesarrollo/CJ_Articulo_Giorgio_Mosangi.pdf

PARRAS ROSA, M. (1996): "La central de compras: ¿Una necesidad?", en XIII Jornadas Agrícolas y Comerciales, Huelva 11-12 de diciembre de 1996, El Monte, 14 pp.

PORTER , M. (1991): La ventaja competitiva de las naciones. Javier Vergara Editor, Buenos Aires.

RUIZ, P. (1995): "Inmigración y mercado laboral en la horticultura forzada almeriense. Una aproximación", en Demófilo, Revista de cultura tradicional de Andalucía, n 15, Fundación Machado, Sevilla, pp. 135-155.

TERRA ACTUALIDAD (2007): España: cientos de marroquíes acuden a la selección de temporeros agrícolas. Agencia EFE. FreshPlaza. Fecha de publicación: 07/12/2007

UNIMAPS (2005): Mapa hidrológico de Marruecos 2005, en www.unimaps.com 
VALENCIA-FRUITS (1998): «Un centro logístico reexpedidor», en ValenciaFruits. Suplemento: Mercamadrid, 17-2-98, pp. 2-4.

VAN BERGEIJK, J. A. (1995): "La frambuesa, cultivo complementario al fresón. Producciones y mercados», en las XII Jornadas Agrícola Comerciales de El Monte, Huelva.

WIKIPEDIA (2007) I: Geographie_du_Maroc, en http://fr.wikipedia. org/wiki/ G\%C3\%A9ographie_du_Maroc.

WIKIPEDIA (2007) II: Economie du Maroc, en http://fr.wikipedia.org/wiki/ \%C3\% 89conomie_du_Maroc.

WORLDMAPFINDER (2007): Marocco-Africa, en http:// www.worldmapfinder.com/Map_Search.php?ID=/Es/Africa/Morocco\&PG=6. 